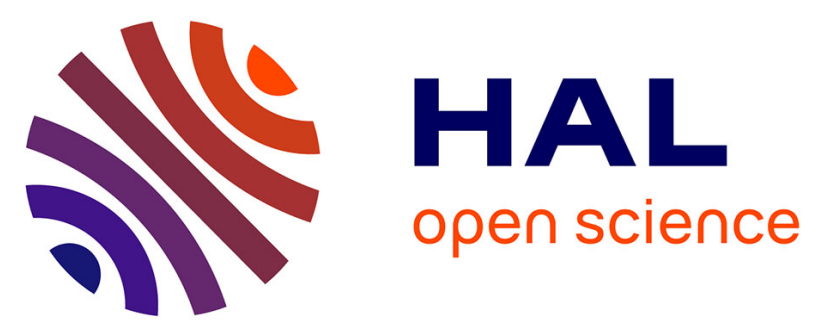

\title{
Potential of field hyperspectral imaging as a non destructive method to assess leaf nitrogen content in Wheat
}

\author{
N. Vigneau, M. Ecarnot, Gilles Rabatel, P. Roumet
}

\section{- To cite this version:}

N. Vigneau, M. Ecarnot, Gilles Rabatel, P. Roumet. Potential of field hyperspectral imaging as a non destructive method to assess leaf nitrogen content in Wheat. Field Crops Research, 2011, 122 (1), p. 25 - p. 31. 10.1016/j.fcr.2011.02.003 . hal-00613201

\section{HAL Id: hal-00613201 \\ https://hal.science/hal-00613201}

Submitted on 3 Aug 2011

HAL is a multi-disciplinary open access archive for the deposit and dissemination of scientific research documents, whether they are published or not. The documents may come from teaching and research institutions in France or abroad, or from public or private research centers.
L'archive ouverte pluridisciplinaire HAL, est destinée au dépôt et à la diffusion de documents scientifiques de niveau recherche, publiés ou non, émanant des établissements d'enseignement et de recherche français ou étrangers, des laboratoires publics ou privés. 


\title{
Potential of field hyperspectral imaging as a non destructive method to assess leaf nitrogen content in Wheat
}

\author{
Nathalie Vigneau ${ }^{\mathrm{a}}$, Martin Ecarnot ${ }^{\mathrm{b}}$, Gilles Rabatel ${ }^{\mathrm{a}}$, Pierre Roumet ${ }^{\mathrm{b}, *}$, \\ ${ }^{a}$ Cemagref, UMR ITAP, 361 rue Jean-François Breton, F-34196 Montpellier, France. \\ ${ }^{b}$ INRA, UMR DIA-PC, Domaine de Melgueil, F-34130 Mauguio, France.
}

\begin{abstract}
Nitrogen is the most important crop limiting factor, thus plant nitrogen status during plant cycle is a key parameter for crop monitoring. Many new techniques, based on leaf optical properties have been proposed for a nondestructive diagnosis to replace Nitrogen Nutrition Index which is a costly and destructive method. We intend here to study leaf nitrogen concentration accessibility from reflectance (400-1000 nm) spectra of whole plants from a field hyperspectral imaging set-up including difficulties related to variable solar lighting and potential specular reflexion. Firstly, we calibrated a chemometrical model between leaf nitrogen concentration and reflectance spectra of flat leaves $\left(R^{2}=0.903, \mathrm{SEP}=0.327 \% \mathrm{DM}\right)$, which validated the sensor and our reflectance correction process. As a second step, we calibrated a chemometrical model between nitrogen concentration and reflectance spectra of individual leaves from isolated plants grown in pots in greenhouse $\left(R^{2}=0.889\right.$, $\mathrm{SEP}=0.481 \% \mathrm{DM})$ or under field conditions $\left(R^{2}=0.881, \mathrm{SEP}=0.366 \% \mathrm{DM}\right)$.
\end{abstract}

\footnotetext{
*Corresponding author

Email address: roumet@supagro.inra.fr (Pierre Roumet)
} 
Pooling the two datasets provided us a relevant model to predict leaf nitrogen content for the two culture conditions $\left(R^{2}=0.875, \mathrm{SEP}=0.496 \% \mathrm{DM}\right)$ suggesting that this technique is promising to assess nitrogen plant parameters with a non destructive method. This tool could be used to follow-up plant nitrogen dynamics criteria or to generate nitrogen spatial cartographies. Keywords: hyperspectral, reflectance, nitrogen concentration, durum wheat

\section{Introduction}

As nitrogen availability in soil affects both yield and harvest quality in most annual cultivated species, nitrogen $(\mathrm{N})$ is considered as key plant nutriment. During vegetative growth soil $\mathrm{N}$ is taken up by roots and assimilated in leaves to synthesize proteins, which are integrated in structural components to constitute cell wall or enzymes in metabolic pathways. In leaves, main part of nitrogen is involved in photosynthetic process through the $\mathrm{Ru}$ bisco (which represents about 50 \% of leaf nitrogen content, Evans (1983)) or enzymes implied in transportation or assimilation of fixed carbon.

As soil $\mathrm{N}$ supply is often limited, nitrogen fertilizer management should be adjusted to crop $\mathrm{N}$ requirements to optimize plant production (Lemaire et al., 2008). To evaluate this plant demand, a well established diagnostic tool is the Nitrogen Nutrition Index(NNI) (Lemaire and Gastal, 1997). NNI is based on comparing actual crop bulk $\mathrm{N}$ concentration with an empirical $\mathrm{N}$ dilution curve. The biomass dependent, critical $\mathrm{N}$ concentration $(\mathrm{Nc})$ is the minimal $\mathrm{N}$ concentration required for maximal growth, developed by Lemaire 
and Salette (1984) and then adapted for most cultivated plants (Justes et al. (1994) for winter wheat, Sheehy et al. (1998) for rice, Colnenne et al. (1998) for rape, Bélanger et al. (2001) for potato and Ziadi et al. (2010) for spring wheat). Obviously the method is laborious and destructive. In other hand, as a strong relationship exists between leaf nitrogen content and photosynthetic pathway, $\mathrm{N}$ leaf indirect estimations based on chlorophyll measurement have been suggested (Baret and Fourty, 1997). Indirect and non destructive N methods derived from chlorophyll measurement through leaf transmittance were proposed; such as Chlorophyll meter SPAD 502@, which provides leaf chlorophyll content based on leaf transmittance at two wavelengths : 650 and $940 \mathrm{~nm}$.

If some authors, as Lee et al. (1999) found a good relationship $\left(R^{2}\right.$ between 0.81 and 0.96 according to the stages of growth) between the chlorophyll content and the actual nitrogen concentration (\%DM), others works demonstrated that this linear relationship nitrogen/chlorophyll does not work in every condition; it could vary according to environmental conditions or/and cultivars (Spaner et al., 2005). To stabilize this relationship the use of ratio between data from experimental plots with overfertilizer reference plot have been recommended (Ziadi et al., 2008) although this reference plot may be sometimes difficult to put in place as underlined by Fox et al. (2001). Anyway, Houlès et al. (2007) connect successfully chlorophyll and NNI with a linear equation ( $R^{2}$ between 0.63 and 0.71 according to growing stage) and Ziadi et al. (2008) measured a determination coefficient of 0.61 between NNI and SPAD values. An integrated approach consists in calculating the NNI 
using remote sensing: the biomass is found through the LAI and the nitrogen content through the chlorophyll content at the canopy scale (Houlès et al., 2007; Lemaire et al., 2008; Chen et al., 2010; Fitzgerald et al., 2010).

In these approaches, the chlorophyll-nitrogen relationship quality is the key point of the nitrogen prediction quality. Yet, this chlorophyll-nitrogen relationship depends on growing season (Evans, 1983) or on nitrogen content range as shown by Evans (1983) and Hidema et al. (1991) at leaf level.

An alternative approach was proposed by Kokaly (2001); it consists to estimate directly plant nitrogen content from a greater wavelength number from visible and infrared spectra as it was classically done in spectroscopy. Wavelength range characteristics and chemometrical models have been investigated to carry out the more efficient models to predict $\mathrm{N}$ plant concentration.

Hansen and Schjoerring (2003) demonstrated that visible and NIR spectra from 400 to $900 \mathrm{~nm}$ coupled with a Partial least Square regression (PLS) allows to calibrate $\mathrm{N}$ plant content with $R^{2}$ of 0.71 and an error of prediction of $0.38 \%$ of dry matter, improving of $24 \%$ nitrogen concentration prediction based on vegetation indices as the NDVI for example. Similar results were reported by Alchanatis and Schmilovitch (2005) from spectra of leaves in the field measured from 530 to $1100 \mathrm{~nm}\left(R^{2}=0.81\right.$ and an error of prediction of $0.27 \% \mathrm{DM}$ ) and by Morón et al. (2007) with spectra (400-2500 nm) collected spectra from excised fresh material $\left(R^{2}=0.89\right.$, with prediction errors 
of 0.64$)$. In this later work, authors pointed out that a robust model could be obtained on fresh material, if appropriate sampling data set representing a large range of environmental conditions and different cultivars was used.

These results suggested that an alternative approach based on an extended number of wavelength coupled with chemometrics could provide direct estimation of nitrogen leaf content. By diversifying calibration samples (culture conditions, genotypes, etc.), the variability of the relation chlorophyllnitrogen should be included in the model.

For this purpose, we built a close-range hyperspectral imaging set-up to take images above wheat plots. In this context, hyperspectral imagery combines several advantages: first, it brings a sufficient spectral resolution for a direct access to nitrogen content, as discussed above. Second, its spatial resolution allows collecting the spectra of individual leaves when observing a whole plot. Since nitrogen content of the well illuminated leaves at the top of the canopy is well correlated to the crop NNI (Farrugia, 2004), the measurement of their individual spectra enables to access NNI in a non-destructive way. Moreover, spatial nitrogen distribution makes it possible to analyse individual plants within crops; this provides an innovative tool to quantify heterogeneity inside canopy, in context of monogenetic cultivars as well as multigenotypic or multispecific crops.

The hyperspectral imagery also presents several advantages compared with punctual spectrometers (such as SPAD 502®). First, it gives spectra of each visible leaf of the plot in one image, which is considerably time 
saving. Furthermore, these spectra are available for each pixel of the leaf surface, providing a better representativeness of the leaf spectral information, compared to a single spectrometric measurement.

In counterpart, such a close-range imaging system presents some specific difficulties related to the management of variable solar lighting, specular reflection and variable illumination level due to leaf inclination. In this paper, we describe successive correction procedures to obtain light-independent reflectance spectra from the original images. Then the calibration of chemometrics models between $\mathrm{N}$ content and reflectance spectra for isolated wheat plants in various conditions (field and greenhouse) are presented and discussed.

\section{Material and methods}

\subsection{Hyperspectral image acquisition system}

All hyperspectral images were acquired with a pushbroom CCD camera (HySpex VNIR 1600-160, Norsk Elektro Optikk, Norway) fitted on a tractormounted motorised rail (see Figure 1). The camera spectral range was from $400 \mathrm{~nm}$ to $1000 \mathrm{~nm}$ divided in 160 bands (3.7 $\mathrm{nm}$ spectral resolution). The first image spatial dimension was determined by the 1600 across-track pixels of the CCD matrix and the second one came from the camera forward movement on the ramp. At $1 \mathrm{~m}$ above the vegetation and with a nadir sighting, the ground track was about $30 \mathrm{~cm}$ and the spatial resolution across track was $0.2 \mathrm{~mm}$ (the lens and the view angle are fixed). The spatial resolution along track was set to $0.5 \mathrm{~mm}$. The integration time, i.e. the time duration during which sensor is storing light energy, was fixed manually by the user 
depending on meteorological conditions (cloudy or sunny weather). Images were then corrected in radiance using sensor characteristics (e.g. spectral sensitivity, etc.) provided by the manufacturer.

\subsection{Reflectance correction}

As a first approximation (i.e. if we consider Lambertian surfaces), radiance $L(\lambda)$ is the product of the target reflectance $R(\lambda)$, which is intrinsic information and the illumination during image acquisition, i.e. in our case solar lighting $E(\lambda)$.

$$
L(\lambda)=R(\lambda) \cdot E(\lambda)
$$

Radiance can not be used directly because illumination depends on date and meteorological conditions. To obtain the variable of interest $\mathrm{R}$, it is thus necessary to know the illumination. For that purpose, spectralon $\AA$ (Labsphere, Inc., New Hampshire, USA) placed in the field of view of the sensor is commonly used because it is a perfect Lambertian diffuser. Another alternative is to use a reference whose spectral characteristics are known. Indeed, in given lighting conditions:

$$
\begin{gathered}
L_{\text {target }}=R_{\text {target }} \cdot E \\
L_{\text {ref }}=R_{\text {ref }} \cdot E
\end{gathered}
$$




$$
R_{\text {target }}=\frac{L_{\text {target }}}{L_{\text {ref }}} \cdot R_{\text {ref }}
$$

where $R$ designs the reflectance, $L$ the radiance, and ref the reference. In this study, we used a ceramic plate appropriate for an every day field use. $R_{\text {ref }}$ was obtained from laboratory measurements.

An example of raw, radiance and reflectance spectra is presented in Figure 2 .

Only reflectance spectra are used for model calibration.

This process is theoretically correct for flat leaves but not for inclinated leaves. Indeed, the leaf inclination toward the sun implies two phenomena which must be taken into account. Due to their dissimilar orientation toward the sun, all leaves do not receive the same level of illumination. They do not receive either the same level than the reference ceramic. Each illumination level is linked to the cosine of the angle between the surface and the light incidence. Because this difference is independent of the wavelength, it can be introduced as a multiplicative factor. So $E_{\text {leaf }}(\lambda)=k_{1} E_{\text {ref }}(\lambda)$ with $E_{\text {leaf }}$ is the lighting received by an inclinated leaf and $E_{r e f}$, the lighting received by the horizontal ceramic plate.

Moreover, the Lambertian approximation above is not exact. Leaves can undergo specular reflexion, i.e. a fraction $k$ of the incident light is reflected by the leaf with no spectral modification (Grant, 1987; Bousquet et al., 2005; Chelle, 2006). Because this specular reflexion is independent of the wavelength (Bousquet et al., 2005), we can write: 


$$
R_{\text {leaf }}(\lambda)=\rho(\lambda)+k
$$

$$
L_{\text {leaf }}=(\rho(\lambda)+k) \cdot k_{1} E_{\text {ref }}
$$

where $\rho(\lambda)$ is the Lambertian part of the leaf reflectance and $k$ is the specular part.

Therefore applying the correction process (equation 4) leads to :

$$
\begin{gathered}
\frac{L_{\text {leaf }}}{L_{\text {ref }}} \cdot R_{\text {ref }}=\frac{(\rho(\lambda)+k) \cdot k_{1} E}{E} \\
R_{a p p}=k_{1} \cdot \rho(\lambda)+k_{2}
\end{gathered}
$$

where $R_{a p p}$ is the reflectance obtained after the correction process, $\rho(\lambda)$ is the Lambertian part of the leaf reflectance and $k_{1}$ and $k_{2}$ are two scalar factors independent of the wavelength.

As a summary, the solar lighting and the leaf inclination imply a multiplicative effect and an additive effect on the obtained reflectance with our correction process.

\subsection{Chemometrical model calibration}

We calibrated chemometrical models between reflectance spectra (400$1000 \mathrm{~nm}$ ) and nitrogen concentration values of individual leaves using Partial Least Square regression (PLS) (Martens and Næs, 1998; Wold et al., 2001). Each dataset, if the number allowed it, was split in a calibration set 
(2/3 of the samples) and a test set (the last third) with the same distribution of nitrogen concentration. We calibrated the model by cross-validation leave-one-out on the calibration set. The best calibration equation and the number of latent variables (LV) were selected on the basis of a large coefficient of multiple determination $\left(R^{2}\right)$ and a low standard error of cross-validation (SECV). SECV is the root mean square error between the actual and predicted values calculated over all cross-validation calibrations. The model was then tested on the test set and its quality was evaluated with the standard error of prediction corrected of the bias $\left(S E P_{c}\right)$ calculated as following:

$$
S E P_{c}=\sqrt{\frac{\sum\left(\widehat{y}_{i}-y_{i}-b i a s\right)^{2}}{N}}
$$

where $N$ is the number of sampling of test set, $y_{i}$, the actual value of the sampling $i$ and $\widehat{y}_{i}$ the predicted value for the sampling $i$. The bias is the mean value of the difference between actual and predicted values (this value can thus be negative). It represents the distance between the prediction and the first bisector. In the following, we will present for each model the $S E P_{c}$ and the bias separately.

In order to overcome leaf inclination and specular reflectance effects, we used common preprocessings. Against additive effects, we used data centering as recommended by Vandeginste et al. (1998). Against multiplicative effects, we used normalisation as recommended by Martens and Næs (1998). The calibration and test steps were done using Matlabß software (TheMathWorks, Natick, MA, USA) and our own Matlab functions. 


\subsection{Datasets}

In a first step, we have focused our attention on flat leaves in order to study potentiality of our sensor and our correction process. Cut flat leaves measurements were similar to laboratory measurements and we wanted to see if we could obtain similar results as those reported previously. In a second step, architecture effects have been taken into account. We saw in section 2.2 that leaf inclination induced illumination level differences and potential specular reflection. We studied whether it was still possible to calibrate a chemometrical model to predict nitrogen when recorded signal was modified by these phenomena.

\subsubsection{Flat leaves}

Flag leaves of about 30 various French durum wheat registrated varieties were cut during the 2009 growing season between flowering and maturity. They were dried and conserved in a cold room. Leaves were put on a flat black background (we used the leaf-clip disc of a field spectrometer (FieldSpec $@$, Analytical Spectral Devices, Inc. (ASD), Boulder, Colorado, USA)). The reference ceramic plate was put beside leaves and the leaves were imaged with the set-up described above. On Figure 3, we can see an image obtained with this protocol.

Once images corrected in reflectance (with the process described in paragraph 2.2), regions of interest were drawn on the leaves to calculate a mean reflectance spectrum for each leaf. The corresponding leaf part was send to laboratory for destructive nitrogen concentration measurement (PerkinElmer elemental analyser (PE $2400 \mathrm{CHN}$, CNRS Cefe Montpellier)). No pre-processing was applied on this dataset because leaves were flat-imaged 
(no specular reflexion, no illumination level issue).

\subsubsection{Isolated plants \\ Greenhouse plants}

During winter 2009-2010, several wheat plants were grown in pots in greenhouse with two nitrogen treatments: with or without nitrogen supply. Four French durum wheat registrated varieties (Neodur, Primadur, Ixos et Lloyd) were imaged at five phenological stages (tillering, 2 nodes, flowering, 450 day-degrees after flowering and maturity). For each plant, the two-upper leaves were marked with coloured plastic collars to be located on the images. After each image (Figure 4), the leaves were cut and send to laboratory for destructive nitrogen measurement. After image correction, regions of interest were drawn on the images to calculate a mean reflectance spectrum for each leaf. In order to take into account illumination level and specular reflexion, two preprocessings were applied on the dataset: normalisation and centering combined in the SNV function.

\section{Field plants}

During the 2010 growing season, wheat field plants were imaged. In order to have isolated plants (to avoid environment effects like multiple reflections) plants were singled by hand. On each plot, 4 leaves were marked with coloured plastic collars and all the no-marked leaves were cut (see Figure 5). This protocol was repeated 5 times (on the $10^{t h}, 20^{\text {th }}$ and $28^{\text {th }}$ of May, the $4^{\text {th }}$ of June and the $1^{\text {st }}$ of July 2010 which correspond to flowering, 165 
day-degrees after flowering, 260 day-degrees after flowering, 407 day-degrees after flowering and maturity). Once again, the SNV function was used as preprocessing.

\section{Results}

\subsection{Nitrogen concentration range}

On table 1 are summarised the results of laboratory experiments for each dataset.

According to the experiments, leaf nitrogen concentration (LNC) varies from $0.4 \% \mathrm{DM}$ to 5.88 \% DM. Reference LNC values have a quite continuous distribution for the flat leaf dataset and a distribution more segmented (in 2 or 3 clusters) for the two other datasets.

\subsection{Models calibrated on various datasets}

The model on flat leaves (called flat leaf model or $M_{f}$ in the following) was calibrated without preprocessing. The best model was obtained with 5 LV (Figure 6).

The optimal processed model on greenhouse plants (called greenhouse model or $M_{g}$ in the following) required the function SNV (data normalisation and centering)and was calibrated with $6 \mathrm{LV}$ (Figure 7).

Data normalisation and centering (SNV function) were also needed to perform the best calibration on field dataset with $4 \mathrm{LV}$ (called field model or $M_{c}$ in the following)(Figure 8).

For each of these three models, high $R^{2}(>0.8)$ mean that PLS is relevant to extract nitrogen information from reflectance spectra. All the models have a negligible bias, which show the prediction accuracy. Calibration 
step for each model shows that LNC can be predicted with a rather low SECV $(\leq 0.45 \% \mathrm{DM})$. Moreover, the test step (only for flat leaf model and greenhouse leaf model), using new data does not increase so much the error $(\leq 0.48 \% \mathrm{DM})$, meaning that there is no overfitting in the model.

\subsection{Cross-application of models}

Each model calibrated on isolated plants was applied on the other and vice versa. As the field dataset nitrogen concentration range was only 0$4 \% \mathrm{DM}$, the field model was applied only on the greenhouse dataset whose nitrogen concentration was inside this range (Figure 9).

All the data of isolated plants (greenhouse and field plants) were used to calibrate a model. The best model (called isolated plant model or $M_{t}$ in the following) required once again the function SNV (data normalisation and centering) and called for only 6 LV (Figure 10).

Figure 11 shows the PLS-coefficients of model calibrated on isolated plants (greenhouse and field plant datasets together). The coefficient values reveal the importance of each wavelength to build the model.The most important coefficients (in absolute value) correspond to chlorophyll absorption bands $(660 \mathrm{~nm})$ but also to other spectral bands: around $500 \mathrm{~nm}, 550 \mathrm{~nm}$, $700 \mathrm{~nm}, 750 \mathrm{~nm}$ and $930 \mathrm{~nm}$.

\section{Discussion}

The objective of our work was to evaluate hyperspectral imaging as a non destructive technology to assess leaf nitrogen content in wheat leaves. In this work we used a sensor with a spectral range from 400 to $1000 \mathrm{~nm}$. Our measure leans so mainly on the photosynthetic nitrogen: chlorophyll, chlorophyll 
a-proteins complexes at $675 \mathrm{~nm}$ (Hopkins, 2003) and some proteins accessible via their $N-H$ bound near $900 \mathrm{~nm}$ (Curran, 1989). As the sun was used as light source, correction in reflectance was firstly carried out and next models was calibrated based on PLS approach. To illustrate the potential of the method, calibrations were built in two steps: firstly on dried excised leaves to specify the capacity of this technology to assess LNC and secondly on whole plant to take into account different leaf angles and variable leaf water content in the model. On excised dried flat leaves, a good accurate model was performed (Figure 6). Statistical parameters of this prediction were pretty good: the $R^{2}$ - which measures the accuracy of regression - was closed to 1 (0.903), the prediction error did not exceed $16 \%$ of the mean of the dataset, and bias was negligible. These results are similar to those obtained by Morón et al. (2007) $\left(R^{2}=0.88\right.$ and $\left.\mathrm{SECV}=0.27\right)$. Obviously they demonstrate the relevance of our sensor and validate our reflectance correction process to infer leaf nitrogen concentration with a good relevance.

In a second step, LNC was inferred from leaf spectra collected on fresh and non excised leaves from greenhouse or field plants. In both cases, calibrations obtained have a good accuracy: $R^{2}$ values remain high $(>0.889)$, prediction errors do not exceed $15 \%$ of the mean of the dataset and, as previously, the bias was negligible (Figures 7 and 8). These results are slight higher than those obtained previously by Morón et al. (2007) $\left(R^{2}=0.82\right.$ and SECV=0.74 in laboratory with a spectrometer equipped with an internal light). The combination of reflectance correction process and pre-processings (data normalisation and centering) was very efficient to take into account different 
leaf inclinations on plants and possible specular reflection: our calibration quality decreases slightly but remains very relevant. These results suggest strongly that it possible to assess leaf nitrogen concentration directly from fresh leaves during plant cycle following a non destructive approach.

Although all these different models provide accurate leaf nitrogen prediction, these models were built on different bases. Therefore, a model built on a given dataset was not relevant to the next one: for example calibration on fresh field leaves could not be used on greenhouse leaves: the prediction bias is too high (Figure 9(a)) indicating that in our case models are dataset dependent. Both low sample number and growing conditions (especially plant nitrogen supply) could explain these differences. Correlations between leaf characteristics (physical properties as thickness, biochemical composition such as chlorophyll, protein content, etc.) and LNC may vary from one experiment to the other and affect the relative importance of the different wavelengths involved in the PLS process. Otherwise, as we underlined it in introduction, the relation between photosynthetic nitrogen and total nitrogen could vary according to environmental conditions, leaf age, etc. Anyway, pooling the two datasets (plants in greenhouse and in field) let us to propose a common model (Figure 10). The high $R^{2}(0.875)$, the low SEPc and the negligible bias mean that variable growing conditions of the samples do not prevent from accessing to nitrogen information. The model coefficients of the plant model Mt (Figure 11) show that many spectral bands are solicited and not only chlorophyll absorption bands. We can thus think that using the whole spectra allow us to include chlorophyll-nitrogen relation variability 
inside the PLS model. Indeed, Hansen and Schjoerring (2003) showed that using PLS improved the prediction (by $24 \%$ ) of the nitrogen concentration with regard to the use of vegetation indices as the NDVI for example. The results obtained by combining all the datasets suggest that including a larger dataset would allow to obtain a satisfactory robustness, provided every possible situation is represented in the samples. For that it is necessary to include several genotypes, several growing years and different growing conditions (in greenhouse and in field) and particularly plant density.

\section{Conclusion}

A few main conclusions can be established from this study. First, nitrogen concentration is accessible from reflectance spectra in 400-1000 nm range not only from dried leaves but also from fresh samples scanned on whole plants. Secondly, reflectance correction process and pre-processings used allow to free oneself from solar lighting issues and plant architecture effects (illumination level and specular reflection) leading to the same quality than the models obtained with laboratory spectra. Moreover, using the whole spectra allow us to overcome variability due to growing conditions, compared to the use of only chlorophyll absorption bands. Nevertheless, a wide calibration set is necessary to calibrate models robust to growing conditions, year, etc.

Finally, this study showed that field close range hyperspectral imaging is a promising technology for non destructive nitrogen monitoring. Its use can be enlarged to physiology or modeling issues. Applying this chemometrical model on whole plot hyperspectral images produces spatial nitrogen cartogra- 
phies. It will be thus possible to follow-up nitrogen dynamics at each leaf level. Data can be introduced in growing models or nitrogen remobilisation models for example.

\section{Ackowledgements}

This study has been funded by the Garicc project of the Q@liméditerannée competitive cluster. We are very grateful to Frédéric Compan and Béatrice Ramora for their help for field experiments.

\section{References}

Alchanatis, V., Schmilovitch, Z., 2005. In-field assessment of single leaf nitrogen status by spectral reflectance measurements. Precision Agriculture $6,25-39$.

Baret, F., Fourty, T., 1997. Diagnosis on the Nitrogen Status in Crops. G. Lemaire (ed), Ch. Radiometric Estimates of Nitrogen Status of Leaves and Canopies, pp. 201-227.

Bélanger, G., Walsh, J., Richards, J., Milburn, P., Ziadi, N., 2001. Critical nitrogen curve and nitrogen nutrition index for potato in eastern canada. American Journal of Potato Research 78 (5), 355-364.

Bousquet, L., Lachérade, S., Jacquemoud, S., Moya, I., 2005. Leaf brdf measurements and model for specular and diffuse components differentiation. Remote Sensing of Environment 98 (2-3), 201-211. 
Chelle, M., 2006. Could plant leaves be treated as lambertian surfaces in dense crop canopies to estimate light absorption? Ecological Modelling 198 (1-2), 219-228.

Chen, P., Haboudane, D., Tremblay, N., Wang, J., Vigneault, P., Li, B., 2010. New spectral indicator assessing the efficiency of crop nitrogen treatment in corn and wheat. Remote Sensing of Environment 114 (9), 1987-1997.

Colnenne, C., Meynard, J., Reau, R., Justes, E., Merrien, A., 1998. Determination of a critical nitrogen dilution curve for winter oilseed rape. Annals of Botany 81 (2), 311-317.

Curran, P. J., 1989. Remote sensing of foliar chemistry. Remote Sensing of Environment 30, 271-278.

Evans, J., 1983. Nitrogen and photosynthesis in the flag leaf of wheat (Triticum aestivum 1.). Plant Physiology 72, 297-302.

Farrugia, A., Gastal, F., Scholefield, D., 2004. Assessment of nitrogen status of grassland. Grass Forage Sci. 59 (2004), 113-120.

Fitzgerald, G., Rodriguez, D., O'Leary, G., 2010. Measuring and predicting canopy nitrogen nutrition in wheat using a spectral index-the canopy chlorophyll content index (ccci). Field Crops Research 116 (3), 318-324.

Fox, R., Piekielek, W., Macneal, K., 2001. Comparison of late-season diagnostic tests for predicting nitrogen status of corn. Agronomy Journal 93 (3), 590-597. 
Grant, L., 1987. Diffuse and specular characteristics of leaf reflectance. Remote Sensing of Environment 22 (2), 309-322.

Hansen, P., Schjoerring, J., 2003. Reflectance measurement of canopy biomass and nitrogen status in wheat crops using normalized difference vegetation indices and partial least square regression. Remote Sensing of Environment 86, 542-553.

Hidema, J., Makino, A., Mae, T., Ojima, K., 1991. Photosynthetic characteristics of rice leaves aged under different irradiances from full expansion through senescence. Plant Physiology 97, 1287-1293.

Hopkins, W. G., 2003. Physiologie végétale. Bruxelles : De Boeck.

Houlès, V., Guérif, M., Mary, B., 2007. Elaboration of a nitrogen nutrition indicator for winter wheat based on leaf area index and chlorophyll content for making nitrogen recommendations. European Journal of Agronomy 27 (1), 1-11.

Justes, E., Mary, B., Meynard, J., Machet, J., Thelier-Huche, L., 1994. Determination of a critical nitrogen dilution curve for winter wheat crops. Annals of Botany 74 (4), 397-407.

Kokaly, R., 2001. Investigating a physical basis for spectroscopic estimates of leaf nitrogen concentration. Remote Sensing of Environment 75 (2), 153161.

Lee, W., Searcy, S., Kataoka, T., 1999. Assessing nitrogen stress in corn varieties of varying color. In: 1999 ASAE Annual International Meeting. 
No. Paper No 99-3034 in ASAE Meeting Presentation. ASAE, 2950 Niles Rd., St. Joseph, MI 49085-9659 USA, Toronto, Ontario Canada.

Lemaire, G., Gastal, F., 1997. Diagnosis of the Nitrogen Satus in Crops. G. Lemaire (Ed.), Ch. N Uptake and Distribution in Plant Canopies, pp. $3-43$.

Lemaire, G., Jeuffroy, M.-H., Gastal, F., 2008. Diagnosis tool for plant and crop $\mathrm{n}$ status in vegetative stage. theory and practices for crop n management. European Journal of Agronomy 28 (4), 614-624.

Lemaire, G., Salette, J., 1984. Relationship between dynamics of growth and of nitrogen uptake in a pure grass stand. i. study of environmental effects. Agronomie 4, 423-430.

Martens, H., Næs, T., 1998. Multivariate calibration. John Wiley \& Sons.

Morón, A., Garcìa, A., Sawchik, J., Cozzolino, D., 2007. Preliminary study on the use of near-infrared reflectance spectroscopy to assess nitrogen content of undried wheat plants. Journal of the Science of Food and Agriculture 87 (1), 147-152.

Sheehy, J., Dionora, M., Mitchell, P., Peng, S., Cassman, K., Lemaire, G., Williams, R., 1998. Critical nitrogen concentrations: Implications for highyielding rice (oryza sativa l.) cultivars in the tropics. Field Crops Research $59(1), 31-41$.

Spaner, D., Todd, A., Navabi, A., McKenzie, D., Goonewardene, L., 2005. Can leaf chlorophyll measures at differing growth stages be used as an in- 
dicator of winter wheat and spring barley nitrogen requirements in eastern canada? Journal of Agronomy and Crop Science 191 (5), 393-399.

Vandeginste, B. G. M., Massart, D. L., Buydens, L. M. C., De Jong, S., Lewi, P. J., Smeyers-Verbeke, J., 1998. Handbook of Chemometrics and Qualimetrics: Part B. Vol. 20B of Data Handling in Science and Technology. Elsevier Science.

Wold, S., Sjöström, M., Eriksson, L., 2001. Pls-regression: a basic tool of chemometrics. Chemometrics and Intelligent Laboratory Systems 58, 109130.

Ziadi, N., Bélanger, G., Claessens, A., Lefebvre, L., Cambouris, A., Tremblay, N., Nolin, M., Parent, L.-E., 2010. Determination of a critical nitrogen dilution curve for spring wheat. Agronomy Journal 102 (1), 241-250.

Ziadi, N., Brassard, M., Bélanger, G., Claessens, A., Tremblay, N., Cambouris, A., Nolin, M., Parent, L.-E., 2008. Chlorophyll measurements and nitrogen nutrition index for the evaluation of corn nitrogen status. Agronomy Journal 100 (5), 1264-1273. 
Author-produced version of the article published in Field Crops Research, 2011, 122 (1), 25-31.

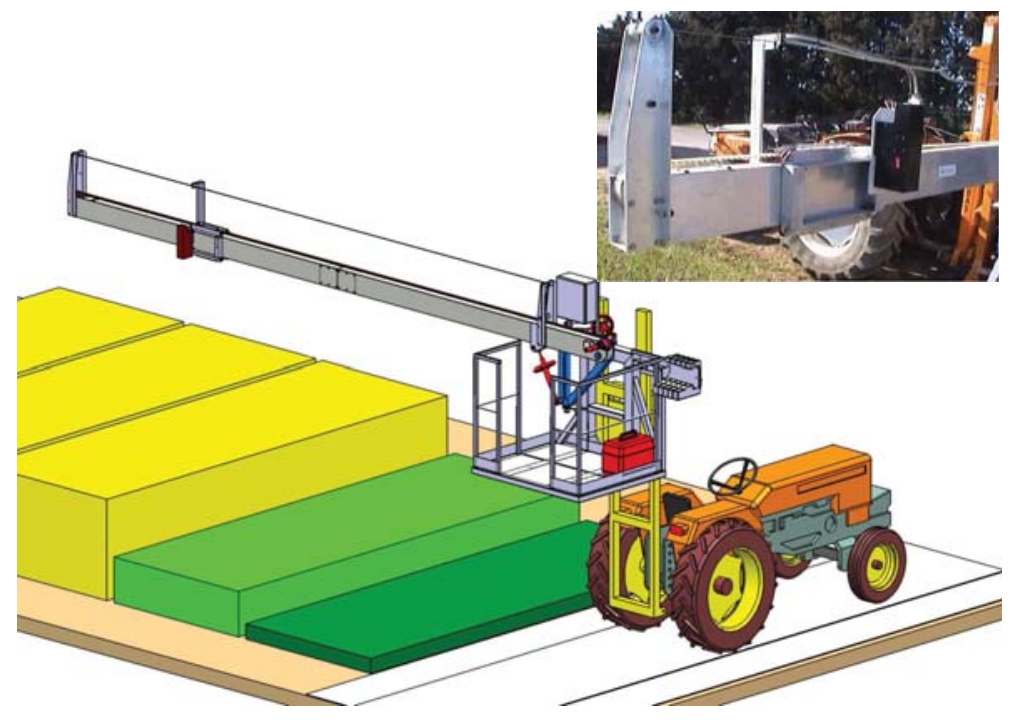

Figure 1: Hyperpsectral imaging set-up. 
Author-produced version of the article published in Field Crops Research, 2011, 122 (1), 25-31.

The original publication is available at http://www.sciencedirect.com

Table 1: Nitrogen concentration range for each dataset: nitrogen concentrations are in $\% \mathrm{DM}$

\begin{tabular}{|c|c|c|c|c|c|}
\hline \hline dataset & $\mathrm{n}$ & $\min$ & $\max$ & mean & standard deviation \\
\hline \hline flat leaves & 146 & 0.4 & 3.78 & 2.07 & 1.05 \\
\hline greenhouse plants & 180 & 0.81 & 5.88 & 3.22 & 1.42 \\
\hline field isolated plants & 56 & 0.71 & 4.2 & 2.37 & 1.07 \\
\hline
\end{tabular}




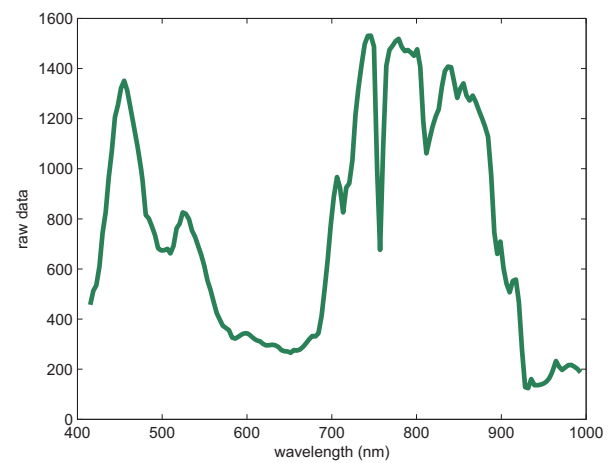

(a)

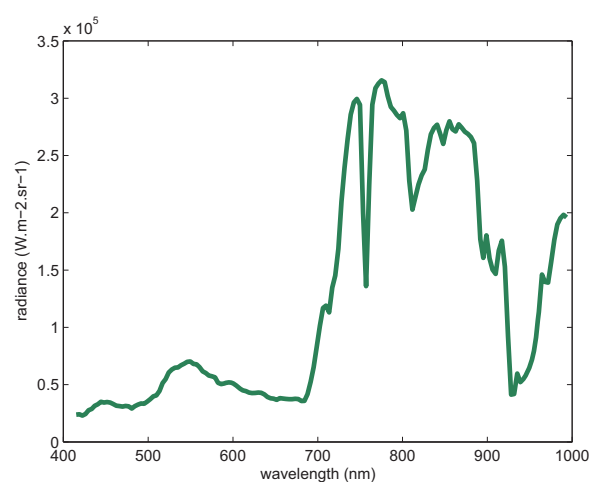

(b)

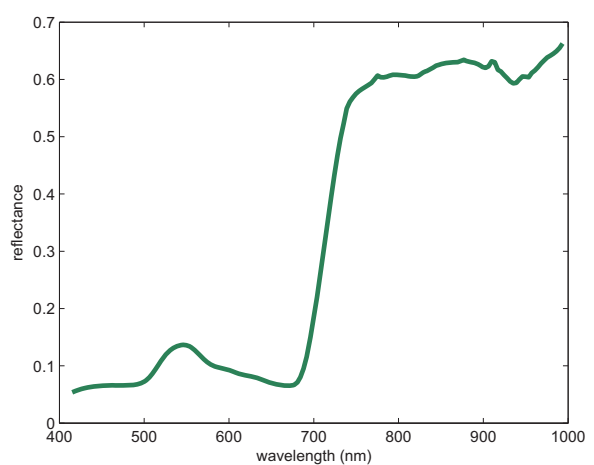

(c)

Figure 2: Example of (a) raw, (b) radiance and (c) reflectance spectra for an isolated leaf. Absorption peaks due to the atmosphere are removed in (c) by the reflectance correction. 
Author-produced version of the article published in Field Crops Research, 2011, 122 (1), 25-31.

The original publication is available at http://www.sciencedirect.com

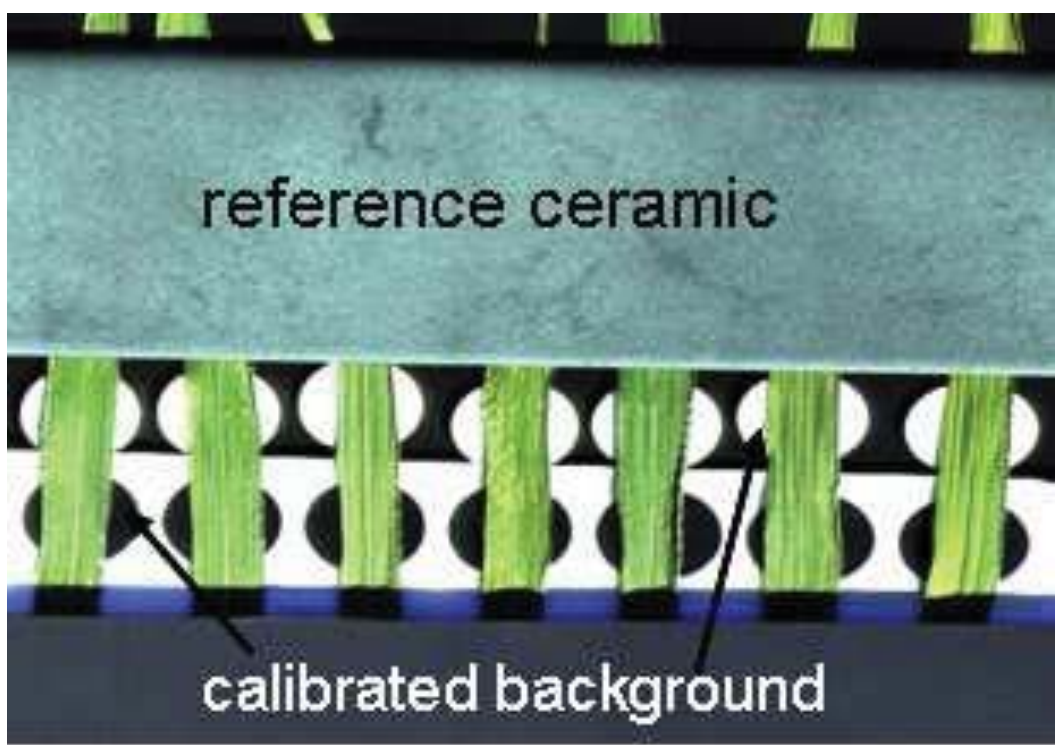

Figure 3: Example of an image obtained with the protocol for flat leaves (black and white background discs were set but only black ones are used in this study). 
Author-produced version of the article published in Field Crops Research, 2011, 122 (1), 25-31.

The original publication is available at http://www.sciencedirect.com

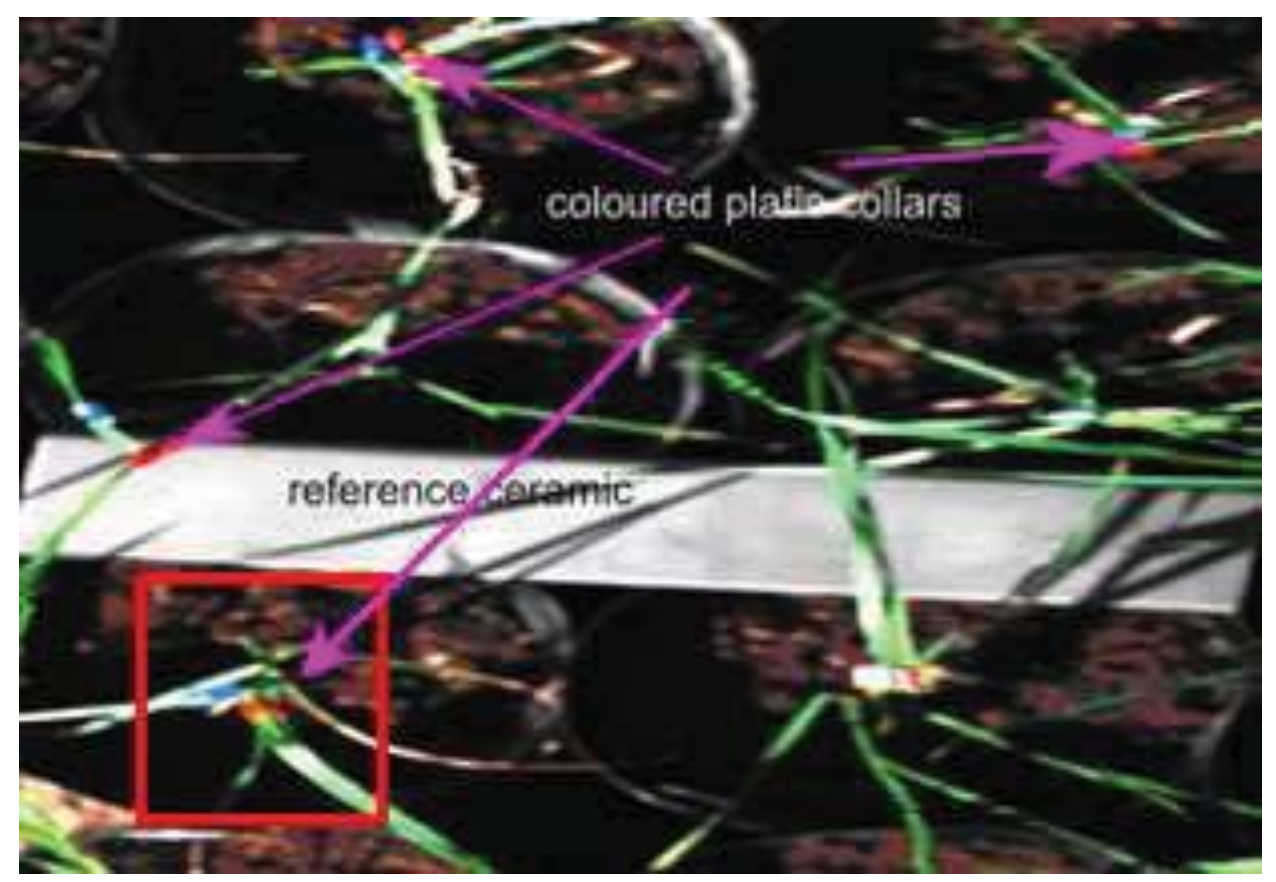

(a)

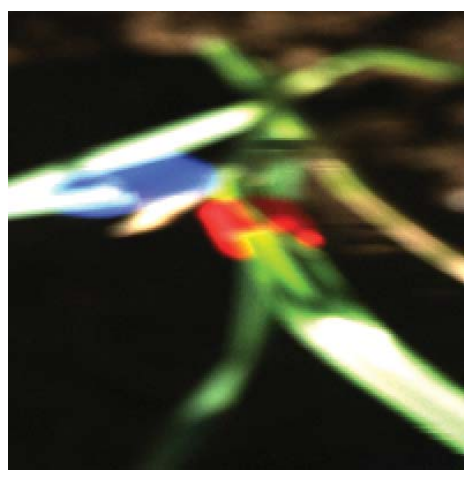

(b)

Figure 4: Example of an image obtained with the protocol for greenhouse plants. 
Author-produced version of the article published in Field Crops Research, 2011, 122 (1), 25-31.

The original publication is available at http://www.sciencedirect.com

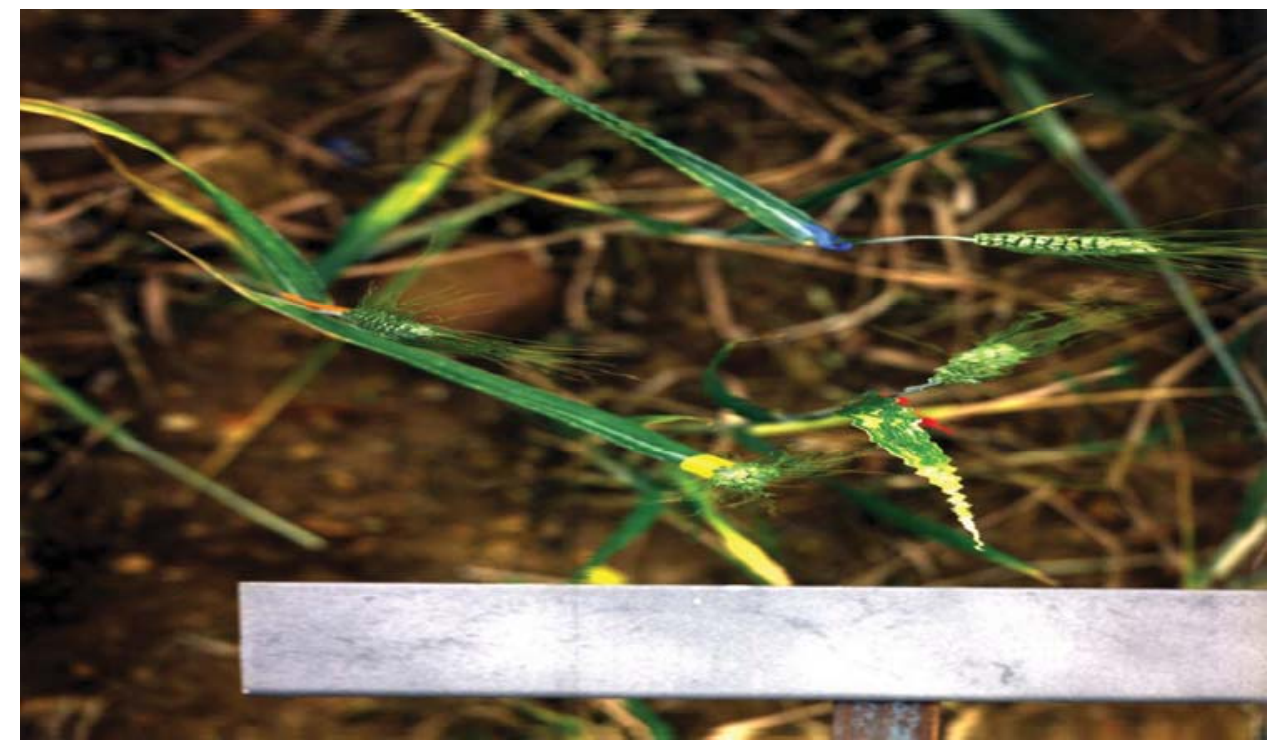

Figure 5: Example of an image obtained with the protocol for field isolated plants. 
Author-produced version of the article published in Field Crops Research, 2011, 122 (1), 25-31.

The original publication is available at http://www.sciencedirect.com

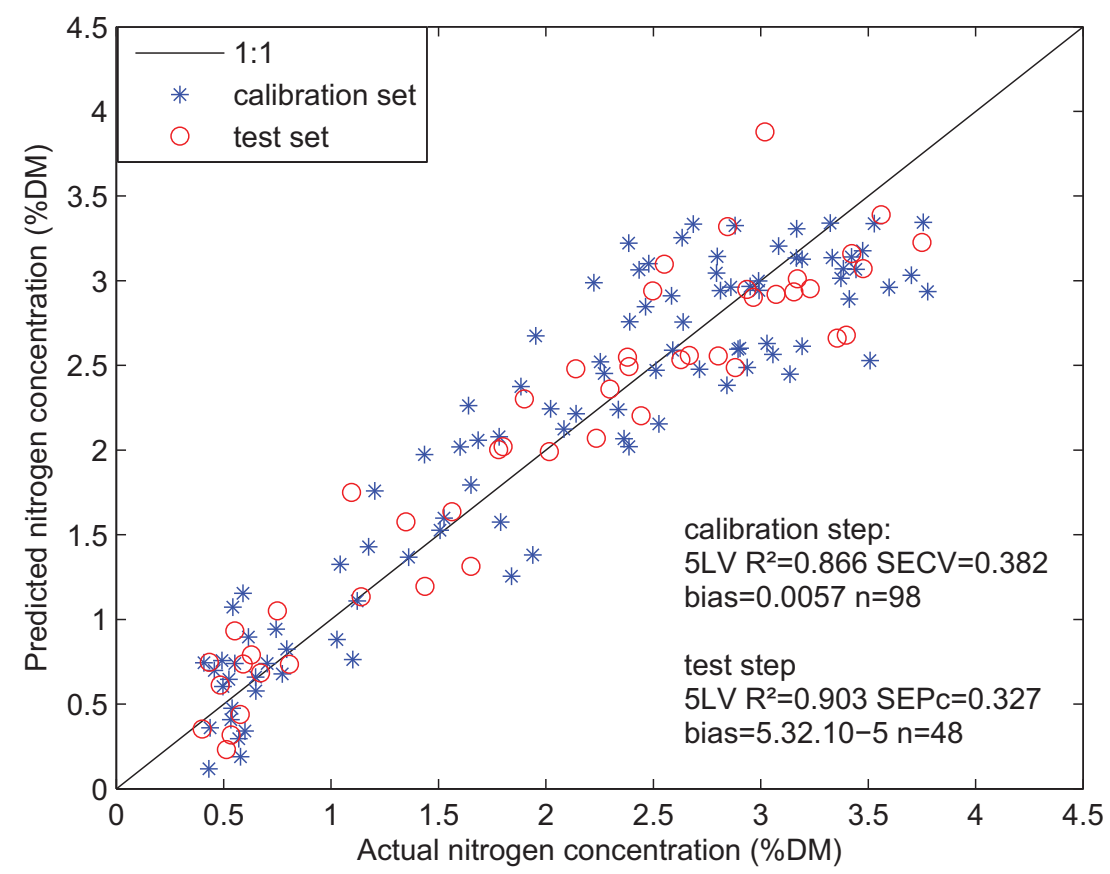

Figure 6: Results of the chemometrical model calibrated on flat leaves with no preprocessing and 5LV (blue stars for calibration step and red circles for test step). 
Author-produced version of the article published in Field Crops Research, 2011, 122 (1), 25-31.

The original publication is available at http://www.sciencedirect.com

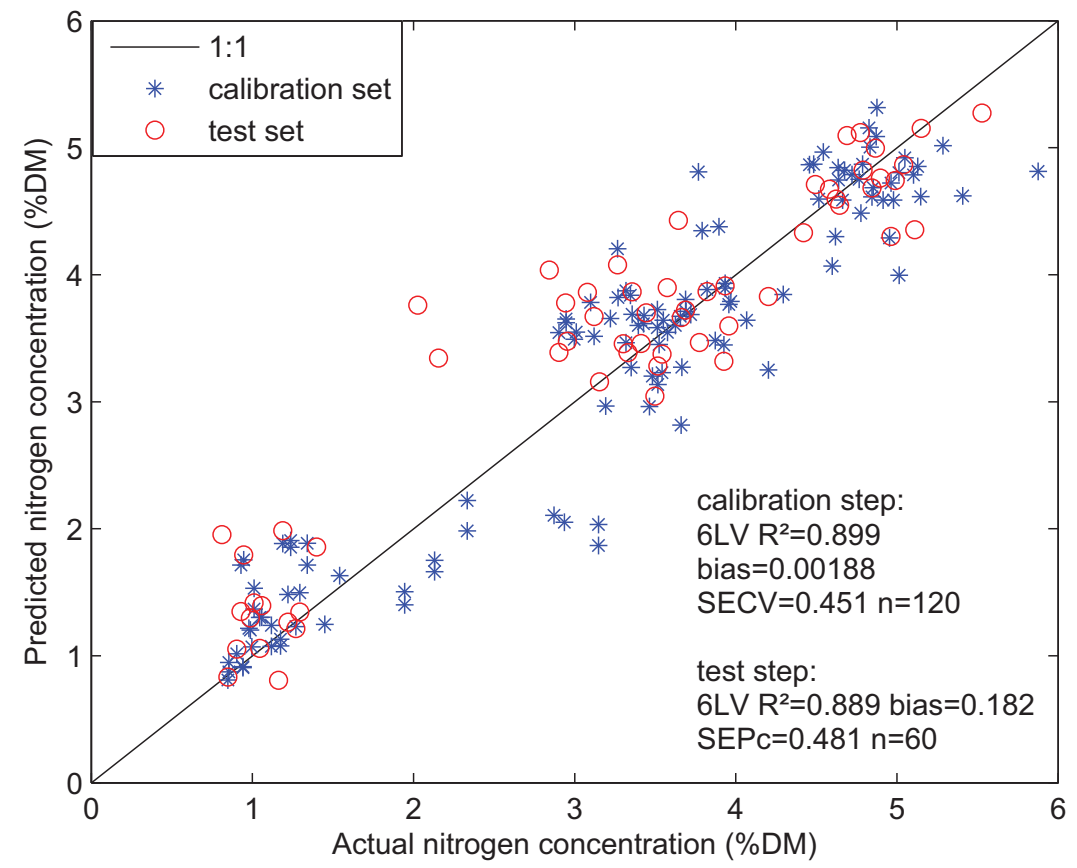

Figure 7: Results of the chemometrical model calibrated on greenhouse plants with SNV and 6LV (blue stars for calibration step and red circles for test step). 
Author-produced version of the article published in Field Crops Research, 2011, 122 (1), 25-31.

The original publication is available at http://www.sciencedirect.com

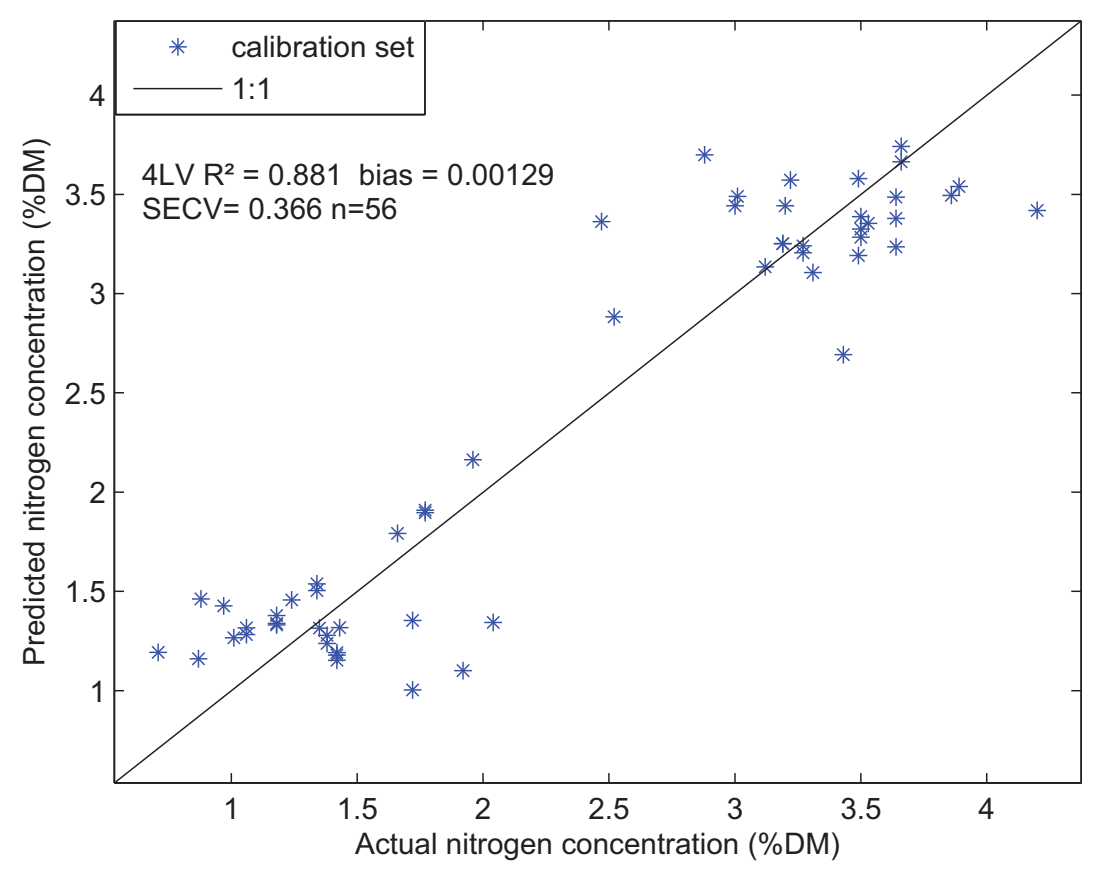

Figure 8: Results of the chemometrical model calibrated on field isolated plants with SNV and $4 \mathrm{LV}$. 


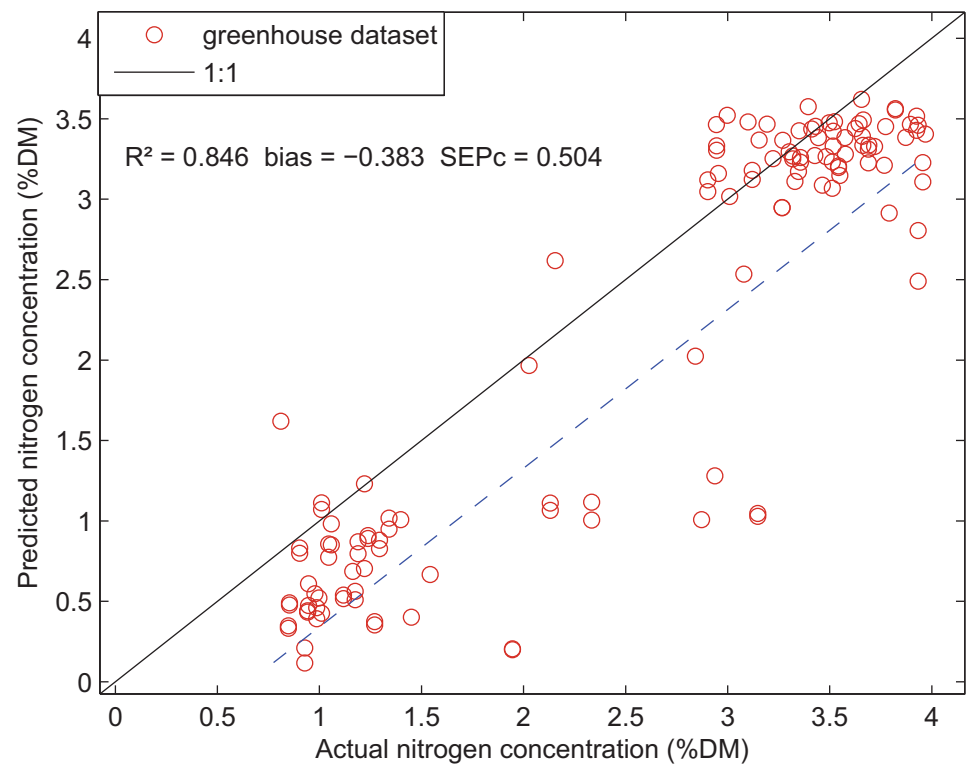

(a)

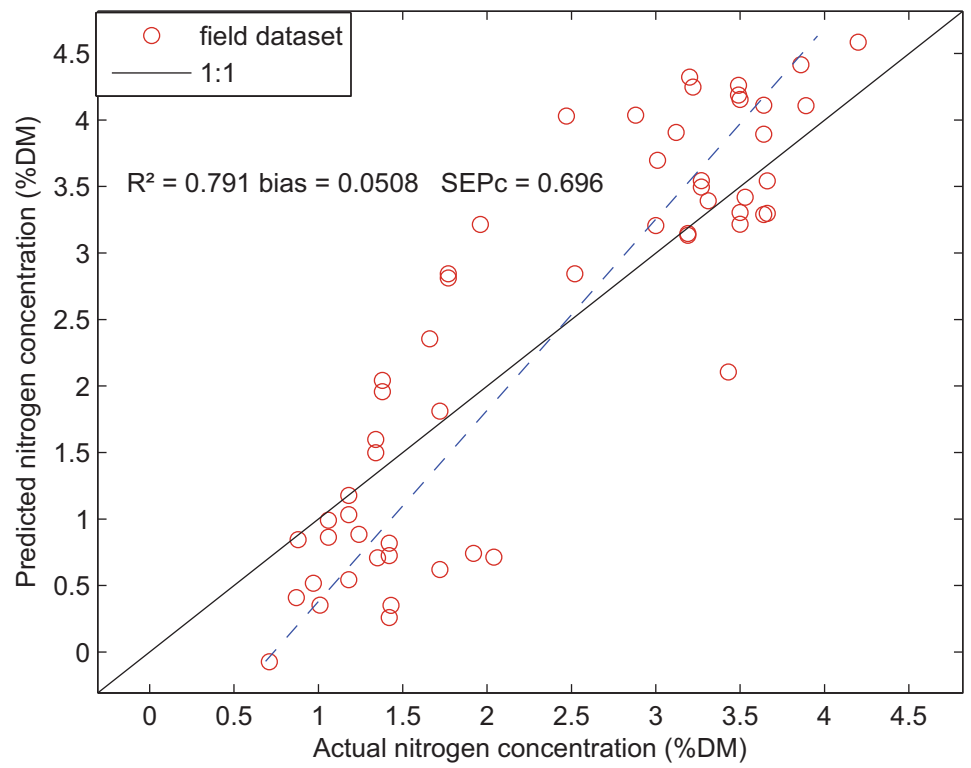

(b)

Figure 9: Cross-application of the models 32librated on isolated plants: (a) model calibrated on field plants applied on greenhouse plants, (b) model calibrated on greenhouse plants applied on field plants. 
Author-produced version of the article published in Field Crops Research, 2011, 122 (1), 25-31.

The original publication is available at http://www.sciencedirect.com

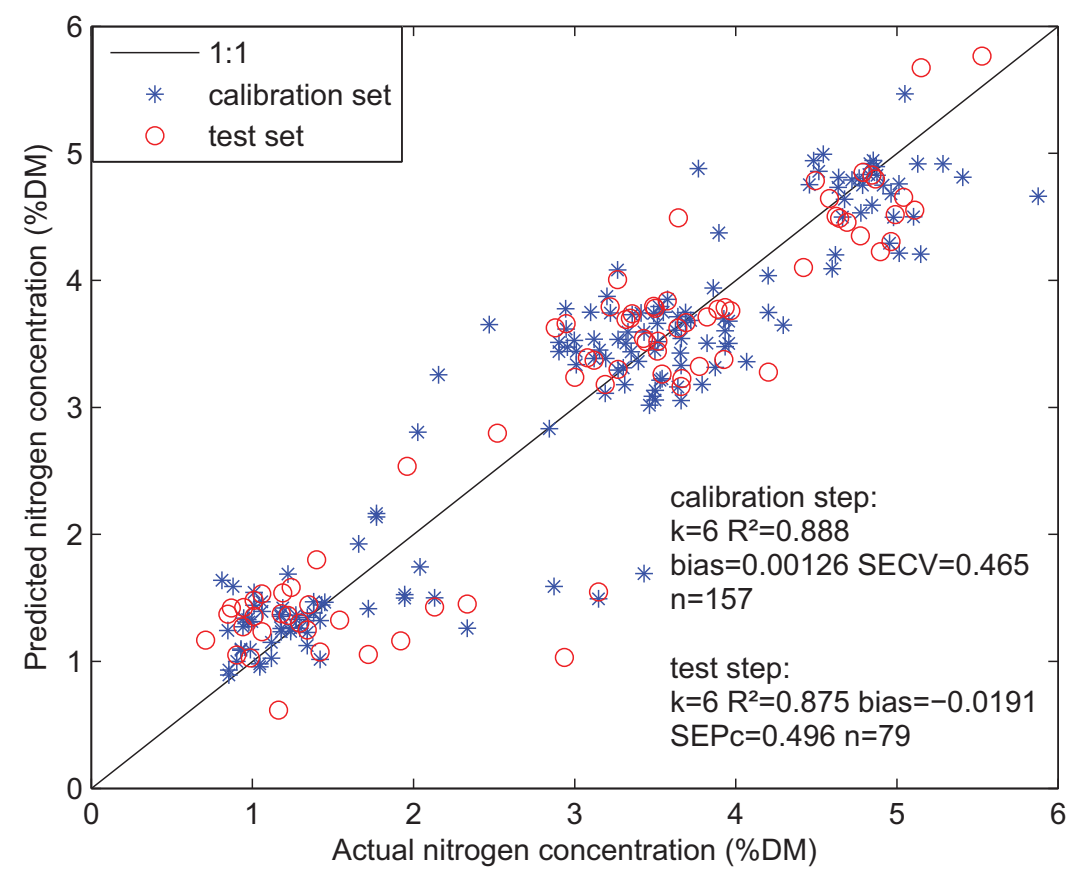

Figure 10: Results of the chemometrical model calibrated on isolated plants (greenhouse and field plants) with SNV and 6LV (blue stars for calibration step and red circles for test step). 
Author-produced version of the article published in Field Crops Research, 2011, 122 (1), 25-31.

The original publication is available at http://www.sciencedirect.com

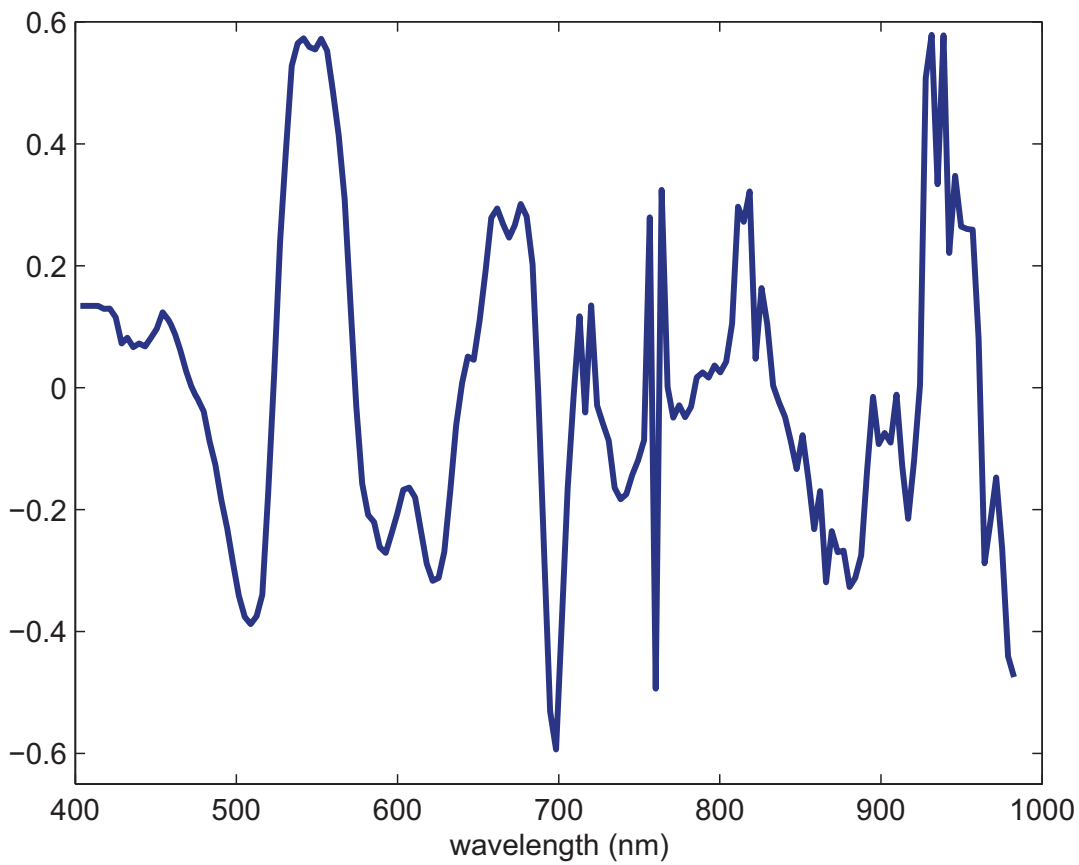

Figure 11: PLS-coefficients for the isolated plant models $M_{t}$. 